\title{
Midland Silicones Memories
}

\author{
Michael J. Owen
}

Received: 6 April 2011 / Accepted: 19 April 2011 /Published online: 4 May 2011

(C) Springer Science+Business Media B.V. 2011

One of the world's most significant silicone manufacturing sites is in Barry, South Wales, owned by Dow Corning Corporation. Silicones have been produced at this site since 1952 but for the first two decades the company was known as Midland Silicones Ltd. (not to be confused with the Midland Silicon Company L.L.C.). Midland Silicones was my entrance to the fascinating world of organosilicon materials and I hope that these indulgent reminiscences will trigger memories for some readers and acquaint others with this bygone joint venture.

The two partners in the new company were Dow Corning Corporation of Midland, Michigan, USA and Albright and Wilson with headquarters at Oldbury in the West Midlands of England. Given these geographical realities one supposes that little time was devoted to deciding the name of the new company. To the American joint owners it was usually referred to as Midsil but to my colleagues at least, it was either Midland Silicones in full or shortened to MS, never Midsil. For the other partner, Albright and Wilson, the move into silicones was not particularly adventurous from an elemental viewpoint. Their operation was based on the chemistry of phosphorus. Silicon and phosphorus are adjacent members of the periodic table. Despite this elemental proximity Albright and Wilson's contribution to the new venture was financial and managerial not technical. Much of the necessary capital came from the Oldbury firm as did the initial senior staff, including John Hughes, the head man at Barry throughout the Midland Silicones era. For several years such aspects as

Guest Editorial: Michael J. Owen

M. J. Owen $(\square)$

Michigan Molecular Institute,

1910 West Saint Andrews Road,

Midland, MI 48640-2696, USA

e-mail: michaelowen01@chartermi.net professional hiring were dealt with through the Albright and Wilson organization. Dow Corning with its almost ten years experience with silicones provided the technical knowledge and expertise as well as many materials and intermediates.

The so-called Muller-Rochow direct process reaction lies at the heart of the silicone industry and the Dow Corning experience with this process was key to its establishment in Barry. It is still the standard technology for industrial preparation of organosilicon compounds, but even today there are few such primary reactors because of the complexity of the process and its high capital requirements. The process is based on the reaction of methyl chloride with silicon metal in a fluidized bed. Only Wacker Chemie AG and Midland Silicones Ltd. had this capability in Europe in the 1950s.

The Barry site had originally been developed in the Second World War to extract magnesium from sea water. Given that the UK's longest river, the Severn, and several other rivers make the Bristol Channel at Barry rather less salty than it is further west, this location decision does make one wonder. That venture was called Ocean Salts, a name that persisted for quite a few years among some local inhabitants after the establishment of Midland Silicones. I would like to think there are a few residents who still refer to the present site by the name I first knew it by although forty years on I realize this is rather unlikely. When I first saw the Barry site I was struck by its large concrete bowls. How clever, I thought; catchment basins for containing spilled silicone fluids in an emergency, little knowing I was looking at the settling bowls used in the old magnesium extraction process. The larger ponds behind the factory, possibly another remnant of Ocean Salts, were home to nesting swans and other wildlife. To Dow Corning's credit, expansion at this site has not impaired this coexistence with 
nature. Currently, the company operates a nature center adjacent to the production site for use by schools and local groups.

The Barry site was not the only place Midland Silicones folk could be found. The sales and marketing departments were situated in Reading and in time, to the best of my recollection, there were sales offices in Vienna, Johannesburg, Singapore and New York. During the fifties Midland Silicones expectedly took its lead from Dow Corning but the sixties brought considerable innovation from Barry including Sioplas E polyethylene cross-linking, solventless paper coatings, hydrosilylation (system D) rhodium catalysis, wool treatments and anionic polymerization to name a few. Towards the end of the 1960s Midland Silicones profits began to suffer, partly because of overenthusiastic expansion of production facilities and new hires but also due to a more general recession in Britain's industrial situation. For example, a new primary reactor for basic chlorosilanes was started in 1967 to augment the original 1950s one; the silicone rubber facility was also extended that year. Silicone fluid capacity was doubled the year before. A new plant to produce silicone resins as well as an expansion of R\&D facilities was also underway during the late 1960s [1].

Matters came to a head at the beginning of the 1970s. Government and unions in the UK were growing increasingly apart. In 1970 over 10 million working days were lost through strike action including those of nurses, dockers and electricity workers [2]. Power outages were commonplace. Desperate action by Midland Silicones management was required. During 1970 and 1971 over a third of the 1200 strong workforce were made redundant and full control passed to Dow Corning for 8.3 million dollars [3] as Albright and Wilson was in as bad a shape as most of the rest of UK industry at that time. In 1971 Tenneco Inc. became part owners of Albright and Wilson, assuming full ownership in 1978. For a while our company was known as Midland Silicones/Dow Corning, then Dow Corning/Midland Silicones and finally, simply, Dow Corning. I am reliably informed that there is just one person still employed at the Barry site who hired on in the Midland Silicones era.

This short memoir has focused on the beginning and end of Midland Silicones but in between it was a stimulating place to work with lots of freedom and plenty of scientific and technical challenges. For me personally, the years I was encouraged to explore the mechanisms of urethane foam stabilization, antifoaming fundamentals and to design novel new silicone surfactants and surface modifying copolymers were particularly satisfying. I greatly valued the opportunity to publish and participate in key conferences early in my career. I have fond memories of many R\&D colleagues who made it all possible but will only mention one, Norman Lloyd who directed the Research Department from its formation in the early 60s. Both he and I attended Cardiff High School for Boys so hurrah for the old-boys network.

The name of Midland Silicones Ltd. lives on in one unexpected way. If you search the web for it, almost all the hits will concern the case of Scruttons Ltd. (a shipping company) versus Midland Silicones Ltd. This was a landmark House of Lords action concerning contract law that resulted in clauses being added to contracts to protect
Fig. 1 Aerial view of Midland Silicones Ltd. site in Barry, Wales in the early 1960 s. (Courtesy of Robin Pitcher and Dow Corning Ltd.). WGS84 Lat/Lon $51^{\circ} 24^{\prime} 36^{\prime \prime} \mathrm{N} / 3^{\circ} 14^{\prime} 21^{\prime \prime} \mathrm{W}$

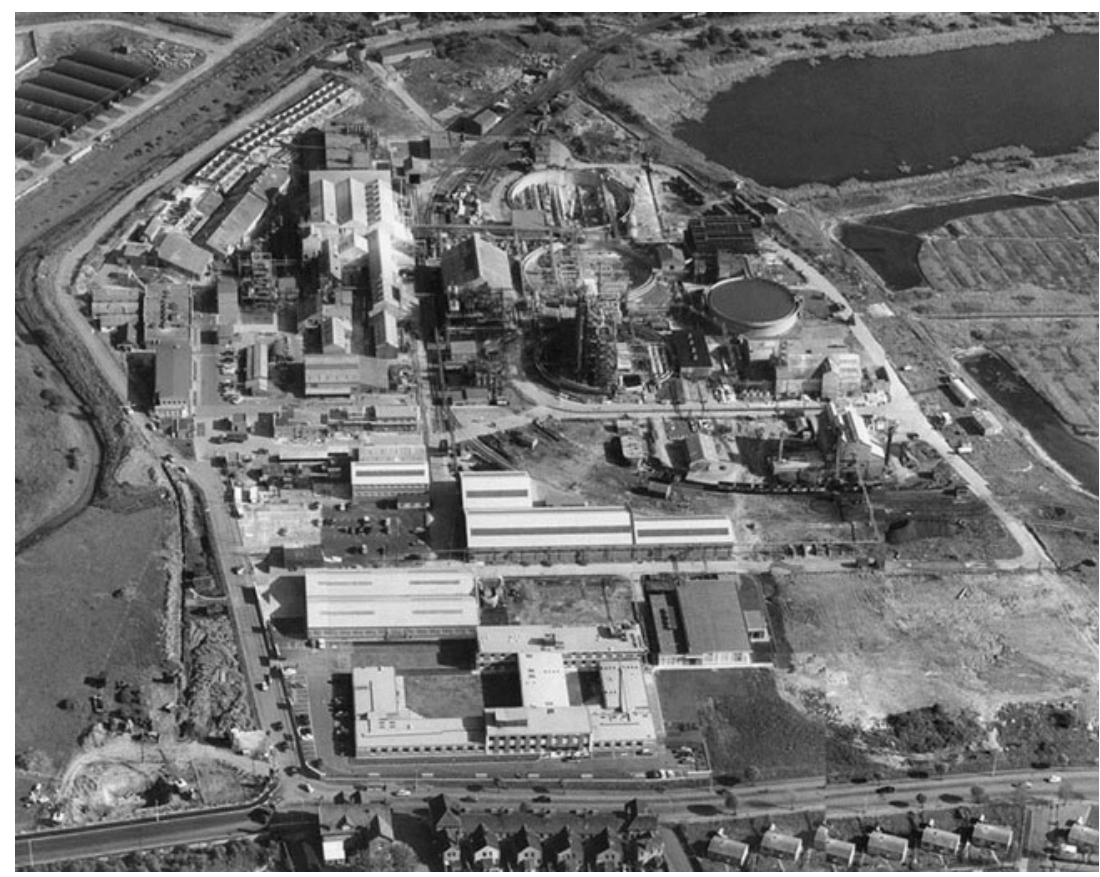


third parties. It dealt with a drum of silicones that was damaged by stevedores while in shipment from Dow Corning in the USA to Midland Silicones in the UK.

The site photograph was taken in the early 1960s looking in a SE direction (see Figure 1). The buildings in the lower center housed TS\&D, analytical, the library and administrative offices. The bowls are in the upper middle with the chlorosilanes distillation column in the nearest of the three. The buildings to the left are fluid, resin and rubber finishing facilities and the power station is at center right. Note also the "prefabs" across Cardiff Road in the bottom right. Built in large numbers after WW11 and meant to last just a decade, these are long gone but others are still inhabited today.

\section{References}

1. Tom Clemett's History of Barry, http://www.barrywales.co.uk/ tomclemett/industrycardiffrd.asp

2. www.natonalarchives.gov.uk/cabinetpapers/

3. Warrick EL (1990) Forty Years of Firsts. McGraw-Hill, Inc., New York, p 276 